\title{
Intramedullary Spinal Cord Arteriovenous Malformation with Hematomyelia without Subarachnoid Hemorrhage -Case Report-
}

\author{
Susumu OHARA, Takashiro OHYAMA, Atsufumi MOTO \\ and Fumiyuki MOMMA
}

Department of Neurosurgery, Yao Tokushukai Hospital, Yao, Osaka

\begin{abstract}
A 36-year-old male presented with an intramedullary spinal cord arteriovenous malformation with hematomyelia but without subarachnoid hemorrhage, manifesting as lower body sensory impairments and leg weakness. Magnetic resonance imaging was used to localize the lesion. Myelotomy allowed excision of the lesion and his sensory impairments improved.
\end{abstract}

Key words: spinal cord, arteriovenous malformation, hematomyelia

\section{Introduction}

Most spinal cord arteriovenous malformations (AVMs) manifest as slowly progressive myelopathy. Rupture occasionally causes acute onset, usually of subarachnoid hemorrhage (SAH). One study showed that about $89 \%$ of cases had a clinical history of slowly progressive non-traumatic myelopathy such as motor or sensory deficit, sphincter or sexual dysfunction, or chronic back pain. Only $11 \%$ of the cases had acute onset, usually associated with SAH. $\left.{ }^{6}\right)$ The incidences of SAH reported differ significantly, ${ }^{7,8)}$ but cases with hematomyelia but not SAH are very rare. Intramedullary hematoma (hematomyelia) without SAH is possible, ${ }^{10)}$ but no case has been reported.

Here, we describe a case of spinal cord AVM with hematomyelia but without SAH.

\section{Case Report}

A 36-year-old male was admitted with complaints of back pain and paraparesis. He had a history of similar pain 10 and 16 years previously, without residual neurological deficit. He experienced sudden

Received February 27, 1992; Accepted October 29, 1992 onset of back pain radiating to the right lower $a b-$ domen and upper thigh area on December 26, 1989. Next day, he developed a pain in the left leg with subsequent paraparesis which was worse on the right side. He was admitted to a nearby hospital with severe gait disturbance and urinary retention on December 28, 1989. He was transferred to our hospital as his symptoms had deteriorated during the evening of the same day.

Neurological examination revealed that he was alert, with intact cranial nerves and no neck stiffness. An indwelling urinary catheter had been inserted. He was suffering from spontaneous pain in his lower back and lower abdominal area radiating to the left thigh. Weakness of both legs was evaluated at $1-2 / 5$. Deep tendon reflexes were normal in the upper extremities and absent in the lower extremities. No plantar responses were obtained. The bulbocavernosus reflex was absent. Sensory examination showed hypalgesia and hypesthesia below his lower abdominal area.

Plain $\mathrm{x}$-ray films and computed tomographic scans of the thoracolumbar spine on December 28 showed no abnormalities. Lumbar puncture found a watery clear fluid and a pressure of $135 \mathrm{mmH}_{2} \mathrm{O}$. Myelograms showed no disturbances in the passage of the contrast material. Analysis of the cerebrospinal fluid showed a cell count of $4 / \mathrm{mm}^{3}$ 
(monocyte 1, polymorpholeukocytes 3 ), protein level $15.6 \mathrm{mg} / \mathrm{dl}$, sugar level $56 \mathrm{mg} / \mathrm{dl}$, and $\mathrm{Cl} 124$ $\mathrm{mEq} / \mathrm{l}$. Magnetic resonance (MR) imaging of the thoracolumbar spine showed a spotty high-intensity area surrounded by low intensity in the anterior spinal cord at the Th10/11 level on the $\mathrm{T}_{1}$-weighted image. An extensive low-intensity lesion was noted inside the cord from the Th8 to Ll levels on the $\mathrm{T}_{2}{ }^{*}$ weighted image. Enhancement with gadoliniumdiethylenetriaminepenta-acetic acid (Gd-DTPA) was
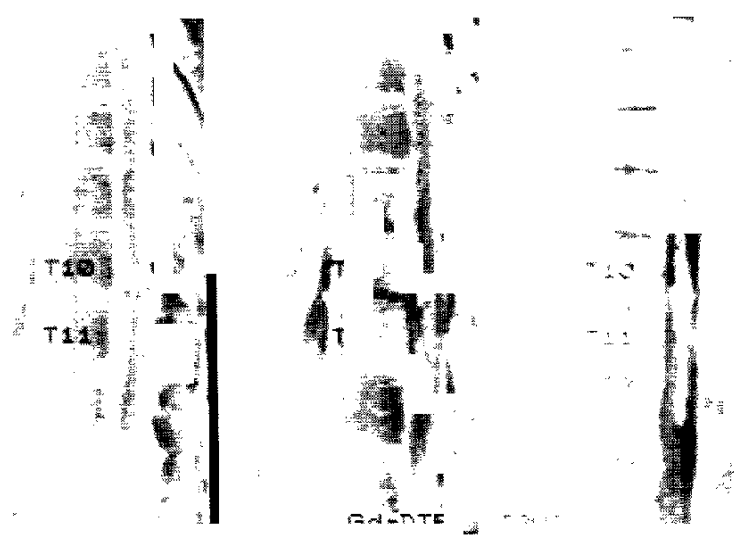

Fig. 1 Sagittal MR images of the thoracolumbar spine. left: $\mathrm{T}_{1}$-weighted image (TR 456/TE $28 \mathrm{msec}$, center: Gd-DTPA-enhanced image, right: $\mathrm{T}_{2}{ }^{*}$-weighted image (gradient echo, $\mathrm{TR}$ $300 / \mathrm{TE} 16 \mathrm{msec}$, flip angle $10^{\circ}$ ).

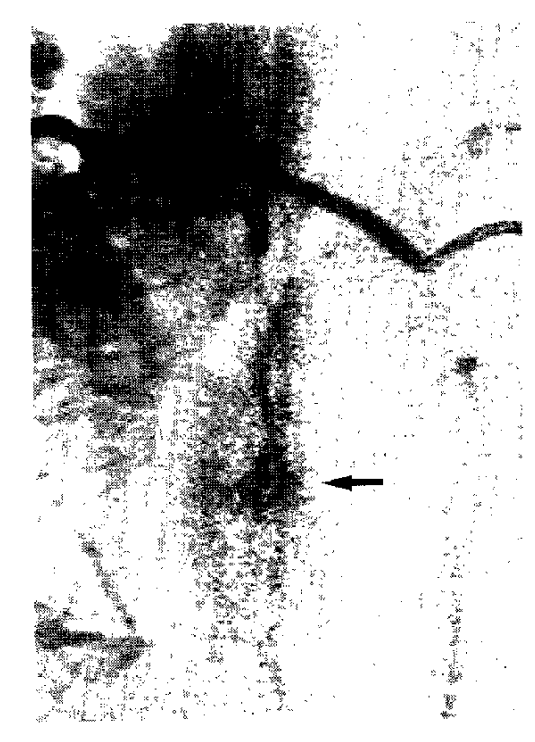

Fig. 2 Spinal angiogram, showing an abnormal artery and a small vascular network (arrow) at the Th10/11 level.

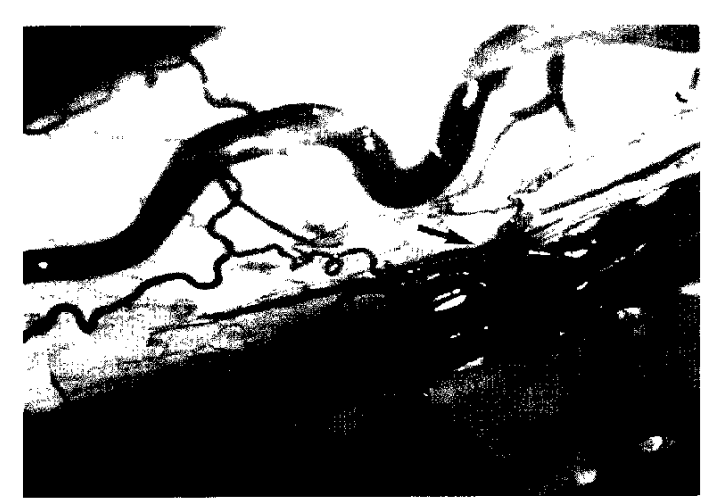

Fig. 3 Operative photograph, showing swollen spinal cord and xanthochromic blots at Th10-12 root entry zones (arrow).

seen only locally at the Th10/11 level (Fig. 1). Spinal angiograms revealed an abnormal artery originating from the right Th8 radicular artery which formed a small vascular network at the Th10/11 level, suggesting a vascular tumor or the nidus of an AVM (Fig. 2).

He continued to deteriorate after admission, becoming completely paraplegic and analgesic below the Th8 level on the right and Th9 level on the left side. Surgical exploration performed on December 29, 1989 disclosed a swollen cord in the lower thoracic area and xanthochromic blots of the right Th10-12 rootlets, suggesting an intramedullary hematoma (Fig. 3). Myelotomy along the right root entry zone allowed excision of the blood clot and abnormal tissues. Histological examination revealed old and fresh hemorrhage and an AVM.

After 6 months, his sensory impairment had improved 7 levels on the right and 5 levels on the left side, but the motor weakness remained unchanged.

\section{Discussion}

Spinal cord AVMs are classified according to location into retromedullary AVM (posterior spinal artery), intramedullary AVM (anterior spinal artery), and extramedullary AVM with medullary venous drainage. ${ }^{1,2,4)}$ Our case was of the second type, an intramedullary AVM fed mainly by the anterior spinal artery. Spinal cord AVM can also be classified according to angiographic appearance into single coiled type, glomus type, or juvenile type. ${ }^{2)}$ This case was the glomus type.

Spinal cord AVM was diagnosed by a combination of clinical symptoms, myelography, and spinal angiography before the development of MR im- 
aging. Myelography was the most important indication followed by spinal angiography. Myelography demonstrated positive findings in $72 \%$ of cases. ${ }^{10}$ However, MR imaging may demonstrate a lesion not shown by myelography. Intramedullary lesions such as nidus, hematoma, thrombus formation, or infarction can be detected by MR imaging. ${ }^{3,599}$

Our patient had a history suggesting minor bleeding from an AVM, and the acute onset suggested massive hemorrhage, but cerebrospinal fluid and myelography examinations were negative. MR imaging demonstrated the lesion, leading to spinal angiography and surgery. Therefore, MR scanning is more useful than myelography in cases of myelopathy for obtaining rapid and accurate diagnosis.

\section{References}

1) Cogan P, Stein BM: Spinal cord arteriovenous malformation with significant intramedullary components. J Neurosurg 59: 471-478, 1983

2) Djinjian R: Embolization of angiomas of the spinal cord. Surg Neurol 4: 411-420, 1975

3) Doppman JL, Di Chiro G, Dwyer AJ, Frank JL, Oldfield EH: Magnetic resonance imaging of spinal arteriovenous malformations. $J$ Neurosurg 66: 830834,1987

4) Ishida $T$, Murayama $S$, Yamaguchi $K$, Urano $Y$, Iwata M: Arteriovenous malformation of the spinal cord. Three-dimensional reconstruction of the in- tramedullary abnormal vessels. Virchows Arch [Pathol Anat] 414: 497-502, 1989

5) Minami $S$, Sagoh $T$, Nishimura $K$, Yamashita $K$, Fujisawa I, Noma S, Itoh $K$, Togashi $K$, Oda $Y$, Matsumoto M, Yamagata S, Kikuchi H, Nakano Y, Konishi J: Spinal arteriovenous malformation: MR imaging. Radiology 169: 109-115, 1988

6) Ommaya AK, Di Chiro G, Doppman J: Ligation of arterial supply in the treatment of arteriovenous malformations. $J$ Neurosurg 30: 679-692, 1969

7) Riche' MC, Modenesi-Freitas J, Djindjian M, Merland JJ: Arteriovenous malformation (AVM) of the spinal cord in children. A review of 38 cases. Neuroradiology 22: 171-180, 1982

8) Rosenblum B, Oldfield EH, Doppman JL, Di Chiro G: Spinal arteriovenous malformations: A comparison of dural arteriovenous fistulas and intradural AVM's in 81 patients. J Neurosurg 67: 795-802, 1987

9) Veerapen RJ, Sbeih IA, O'Laoire SA: Surgical treatment of cryptic AVM's and associated hematoma in the brain stem and spinal cord. $J$ Neurosurg 65 : 188193, 1986

10) Yasargil MG, Symon L, Teddy PJ: Arteriovenous malformation of the spinal cord, in Symon L (ed): Advances and Technical Standards in Neurosurgery, vol 11. Wien, Springer-Verlag, 1984, pp 61-102

Address reprint requests to: S. Ohara, M.D., Department of Neurosurgery, Yao Tokushukai Hospital, 3-15-38 Kyuhoji, Yao, Osaka 581, Japan. 